\title{
POST-MORTEM INTERVAL ESTIMATION BY CEREBRO-SPINAL FLUID FILMS POLARIZATION IMAGES OPTICAL STRUCTURE CHANGING
}

\author{
Marta Garazdiuk ${ }^{1}$, Viktor Bachynskiy ${ }^{2}$, Oleg Wanchuliak ${ }^{3}$, \\ Oleksandr Garazdiuk ${ }^{4}$, Aleksandr Ushenko ${ }^{5}$
}

\begin{abstract}
INTRODUCTION: Post-mortem interval (PMI) estimation has been and remains one of the main issues of forensic medicine. Complex photometric, polarization, and correlation techniques of biological tissue (BT) structure are crucial in this area.

OBJECTIVES: The purpose of this study is to develop and test two-dimensional Stokes-polarimetric mapping of biological layers to evaluate the accuracy of PMI assessments using statistical analysis of post-mortem changes and dynamics of the coordinate distributions for the polarization ellipticity (PE) images of polycrystalline films of liquor (PFL). Coordinate distributions of polarization ellipticity (PE) image values were estimated for each sample of PFL in the optical arrangement of the Stokes polarimeter using the method of twodimensional distributions of Stokes-parameters.

RESULTS: The most sensitive statistics to the post-mortem manifestations in terms of changes to liquor polycrystalline optical networks were those for the 3rd and 4th order. They characterized asymmetry and kurtosis (peak sharpness) of coordinate distributions for polarization ellipticity images of polycrystalline films of liquor. The optimal interval was 32 hours, with accuracy of $60 \mathrm{~min}$, from the method of two-dimensional Stokespolarimetric mapping used.
\end{abstract}

JEL Classification Numbers: I19 DOI: http://dx.doi.org/10.12955/cbup.v4.838

UDC Classification: $616-091$

Keywords: Post-mortem, interval, cerebrospinal, polarization, ellipticity.

\section{Introduction}

Chen, Inamori-Kawamoto, Michiue, Ikeda, Ishikawa\& Maeda, H. (2015), Girela, Villanueva, Irigoyen, Girela, Hernández-Cueto \& Peinado (2008), Parmar \& Menon (2015), Prieto-Bonete, PerezCarceles, \& Luna (2015) considered that post-mortem interval (PMI) estimation had been, and remained, one of the main issues of forensic practice. The time-since-death evaluation is usually based on an assessment of morphological changes in postmortem tissues and body organs. Ushenko O., Dubolazov, Ushenko V, Gorsky, Soltys \& Olar and Ushenko O, Dubolazov, Ushenko Y \& Gorsky (2015a, 2015b), Ushenko V, Olar, Ushenko Y, Gorsky \& Soltys (2015), and Wanchuliak, Ushenko \& Bezhenar, I. L. (2004) have shown, that optical diagnostic methods, using complex photometric, polarization, and correlation techniques of biological tissue (BT) structure, are the most important in this area. These methods of the BT light scattering phenomenon for investigation, with their vector nature, can search the dynamics of data in relationships between post-mortem changes of body tissues and a set of objective photometric, polarization, and correlation parameters of optical images. The ability to monitoring changes over time-since-death demonstrates how new opportunities can provide more objective and accurate post-mortem interval (PMI) estimation. Possibilities of objective PMI estimation by examining post-mortem changes of polarization-inhomogeneous structure in human biological fluids from images has had little exploration until now.

\footnotetext{
${ }^{1}$ Marta Garazdiuk, Higher State Educational Establishment of Ukraine "Bukovinian State Medical University", Forensic Medicine and Medical Law Department, Chernivtsi, Ukraine, m.garazdiuk@gmail.com

2 Viktor Bachynskiy, Higher State Educational Establishment of Ukraine "Bukovinian State Medical University", Forensic Medicine and Medical Law Department, Chernivtsi, Ukraine

${ }^{3}$ Oleg Wanchuliak, Higher State Educational Establishment of Ukraine "Bukovinian State Medical University", Forensic Medicine and Medical Law Department, Chernivtsi, Ukraine

${ }^{4}$ Oleksandr Garazdiuk, Higher State Educational Establishment of Ukraine "Bukovinian State Medical University", Forensic Medicine and Medical Law Department, Chernivtsi, Ukraine

${ }_{5}^{5}$ Aleksandr Ushenko, Y. Fedkovych Chernivtsi National University, Correlation Optic Department, Chernivtsi, Ukraine
} 


\section{Purpose}

The aim of this study is to develop and test two-dimensional Stokes-polarimetric mapping of biological layers as a method to evaluate the accuracy of PMI assessments. This will be based on a statistical analysis of post-mortem changes and dynamics of the coordinate distributions for the polarization ellipticity (PE) images of the polycrystalline films of liquor (PFL).

\section{Materials and Methods}

The study investigated PFLs taken from 52 corpses of both sexes, aged 33 to 91 years, with an accurately known time of death, which ranged from 1 to 41 hours (the main research group), and 20 healthy volunteers (comparison group). The selection of fluid was carried out according to the Dehn \& Asprey (2013) by a suboccipital puncture from the great occipital tank of the corpse and during a spinal anesthesia of healthy volunteers, performed with surgery preparation. In the main group, fluid was selected from cadavers who died because of cardiovascular disease, in 43 cases $(82.7 \%)$, pulmonary tuberculosis, five cases $(9.6 \%)$, and gastrointestinal tumors, four cases $(7.7 \%)$. The next allocation was for time-since-death: 1 to 6 hours comprising 10 cases (19.2\%); 6 to 12 hours, 11 cases (21.2\%); 12 to 20 hours, 10 cases (19.2\%); 20 to 28 hours, 11 cases (21.2\%); and 28 to 34 hours, 10 cases $(19.2 \%)$.

The study of Ushenko O, Dubolazov, Ushenko Y \& Gorsky(2015b) found that the biological fluids on polycrystalline films are characterized by the simultaneous presence of optical isotropic and anisotropic components. According to this broad range of mechanisms for laser radiation parameters (which pass through a biological layer), transformation was implemented. The amount of protein in the cerebrospinal fluid (CSF) changes as a result of biochemical processes in life and after death, when biophysical properties also change. Aksjonova and Starkova (1998) found that free radical oxidation of proteins occurred in any pathology intravitality, leading to protein degradation and formation of toxic fragments, including middle molecules (MM; molecular weight 500-2000 Dalton; D). The chemical composition of the MM is highly heterogeneous and integrates heterogeneous group of agents (peptides, glycopeptides, nucleopeptides, endorphins, and glucuronic acid derivatives). Ermakov (2004) showed that MM level indicators of CSF in people who had died from drug poisoning and cardiovascular disease, gradually increased depending on the time of death, which can be used in the diagnostic identification of PMI. Finehout, Franck, Relkin, \& Lee (2006) estimated the change in the level of proteins in the CSF of living people and the post-mortem changes in their CSF. Fifty-four different types of protein functional groups have been investigated and 14 of these demonstrated a link between increasing amounts of protein and time-since-death. Arroyo, Rosel, \& Marron (2005) found significant differences in protein, cortisol levels (in cases of violent and non-violent death), urea, alkaline phosphatase, and cortisol levels in different age groups. No other chemicals showed statistically significant changes. Thus, the dynamics of biophysical changes in CSF post-mortem largely depend on protein degradation.

Liquor films were formed in identical conditions, by causing a drop of CSF to fall onto optically homogeneous glass. Drying of films was conducted at room temperature $\left(20^{\circ} \mathrm{C}\right)$. The PFL research was carried out in a specialized laboratory of the Correlation Optics Department at the Chernivtsi National University. Mathematical processing and analysis of the PFL images established the timebased dynamics of CSF post-mortem changes.

\section{Optical Circuit and Method of Experimental}

Coordinate distributions (two-dimensional arrays of values in the PFL sample plane) of polarization ellipticity (PE) values were measured at points of the polarization images (Figure 1) in the arrangement of standard Stokes polarimeter, according to O G. Ushenko et.al (2015a).

The six PPL irradiations regime consisted of a parallel $\left(\varnothing=2 \times 10^{3} \mu \mathrm{m}\right)$ cluster of "red" $\mathrm{He}-\mathrm{Ne}$ $\left(\lambda_{1}=0.6328 \mu \mathrm{m}\right)$ on a semiconductor laser (Figure 1).

Polarization irradiator consisted of two polarization elements, the quarter-wave plate, and the polarizer (Figure 1, 3 \& 4).

An image of six PFL samples, using polarization object glass (Nikon CFI Achromat P, the focal length $30 \mathrm{~mm}$, aperture 0.1 , and magnification $4 \times$ ) was projected into the light-sensitive plane of a charge 
coupled device (CCD) camera (The Imaging Source DMK 41AU02.AS, monochrome $1 / 2$ inch CCD, Sony ICX205AL progressive scan) with resolution of $1280 \times 960$, photosensitive matrix size $7600 \times$ $6200 \mu \mathrm{m}$, sensitivity $0.05 \mathrm{~lx}$, and dynamic range of 8-bit.

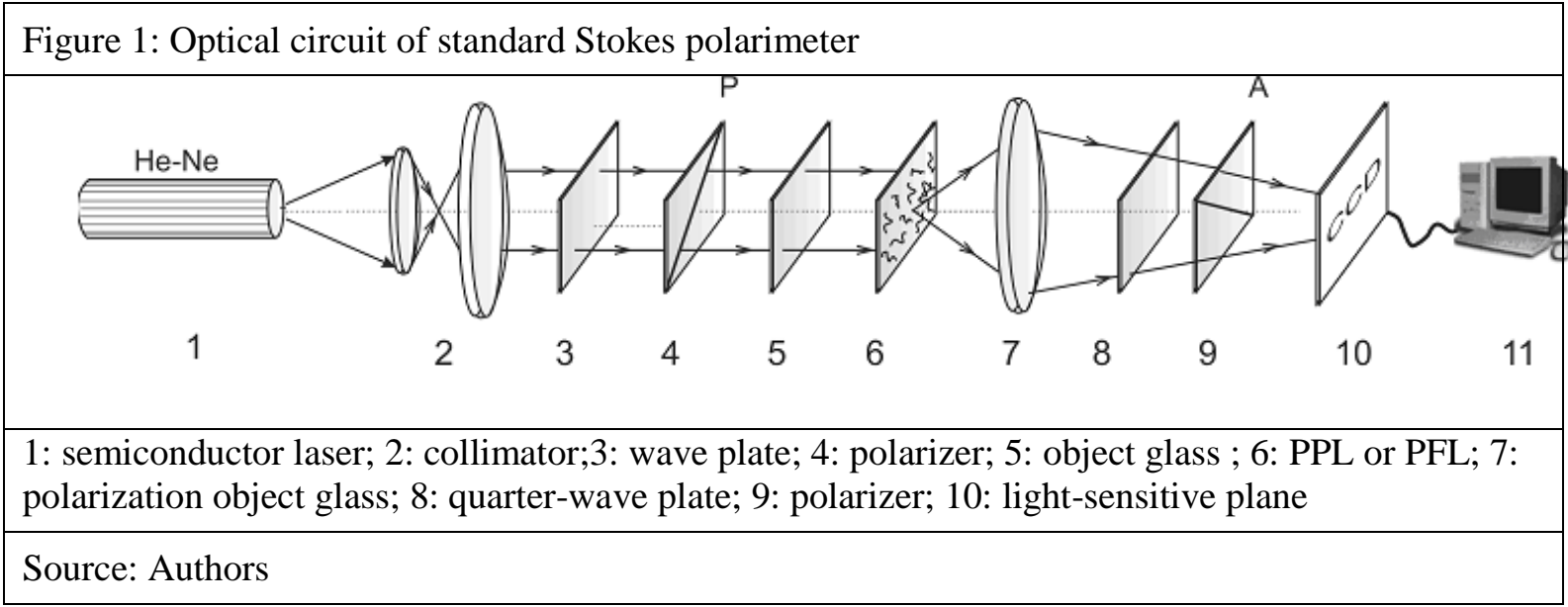

The polarization analysis for the six PFL samples was carried out using a quarter-wave plate and polarizer.

Thus, the main information objects for the optic-physical methods for PMI estimation in our work are a collection of directly measured coordinate distributions of PFL polarization parameters $\beta_{i k}(m \times n)$ :

$$
\beta_{i k}(m \times n)=\left(\begin{array}{ccc}
\left(\beta_{i k}\right)_{11} & . . & \left(\beta_{i k}\right)_{1 n} \\
. & . . & . \\
\left(\beta_{i k}\right)_{m 1} & . . & \left(\beta_{i k}\right)_{m n}
\end{array}\right) \text {; }
$$

The statistics of first $\left(Z_{1}\right)$, second $\left(Z_{2}\right)$, third $\left(Z_{2}\right)$, and fourth $\left(Z_{4}\right)$ orders were used as the main analytical tool to assess the distribution of PFL polarization azimuth values, and further $q(m \times n)$. These statistics were calculated according to the algorithms of O.G. Ushenko et al. (2015a, b) and V. O. Ushenko et al. (2015), as follows:

$$
\begin{gathered}
Z_{1}=\frac{1}{N} \sum_{j=1}^{N} q_{j} ; \\
Z_{2}=\sqrt{\frac{1}{N} \sum_{j=1}^{N}\left(q^{2}\right)_{j} ;} \\
Z_{3}=\frac{1}{Z_{2}^{3}} \frac{1}{N} \sum_{j=1}^{N}\left(q^{3}\right)_{j} ; \\
Z_{4}=\frac{1}{Z_{2}^{4}} \frac{1}{N} \sum_{j=1}^{N}\left(q^{4}\right)_{j},
\end{gathered}
$$

where $N$ is the number of pixels from the CCD-camera photosensitive area.

The measurement of the Stokes vectors for parameters of PFL images was carried out as follows:

- The light-sensitive plane (Figure 1,10) of the CCD-camera consisted of $N=m \times n$ pixels, which allowed simultaneous measurement of the two-dimensional array of intensity:

$$
\left(\begin{array}{ccc}
I_{11} & \ldots & I_{1 n} \\
& I_{j k} & \\
I_{m 1} & \ldots & I_{m n}
\end{array}\right)
$$


in the plane $(x, y)$ of the PFL image. Within each of the PFL images, $j k$-pixel, it was possible to estimate the Stokes parameters through six intensity measurements in these polarization filtration conditions:

$\circ$ polarizer plane (Figure 1,9 ) at angle $\Theta=0^{0}$ to measure the intensity distribution $I_{0}(m \times n)$ of laser images for sampling; and

- polarizer plane turned at angle $\Theta=90^{\circ}$ to measure coordinate values for intensity distribution, $I_{90}(m \times n)$.

- Based on the definition of the Stokes vector, $S$, its first $S_{1}$ and second $S_{2}$ parameters were as follows:

$$
\begin{aligned}
& S_{1}=I_{0}+I_{90} ; \\
& S_{2}=I_{0}-I_{90}
\end{aligned}
$$

$\circ$ polarizer plane (Figure 1,9 ) turned at angle $\Theta=45^{\circ}$ to measure coordinate values for intensity distribution, $I_{45}(m \times n)$.

$\circ$ polarizer plane turned at angle $\Theta=135^{\circ}$ to measure coordinate values for intensity distribution, $I_{135}(m \times n)$.

- The third $S_{3}$ Stokes vector parameter was calculated:

$$
S_{3}=I_{45}-I_{135}
$$

- For the measurement of the fourth Stokes vector parameter, $S_{4}$ :

$\circ$ the quarter-wave plate (Figure 1,8 ) was oriented at highest speed axis at angle $0^{0}$ with polarizer plane transmission oriented at angle $\Theta=45^{\circ}$ to measure coordinate values for intensity distribution of right-circular polarized irradiations, $I_{\otimes}(m \times n)$; and

0 the quarter-wave plate at highest speed axis with polarizer plane at angle $\Theta=135^{\circ}$ to measure coordinate values for intensity distribution of left-circular polarized irradiations, $I_{\oplus}(m \times n)$.

The coordinate distribution of the 4th parameter was identified as:

$$
S_{4}=I_{\otimes}-I_{\oplus}
$$

We obtained two-dimensional values for distribution of the Stokes vector parameter $S_{i=1 ; 2 ; 3 ; 4}(m \times n)$, and calculated the PFL image ellipticity, $\beta$, polarization coordinate values by the following equation:

$$
\beta(m \times n)=0,5 \arcsin \frac{S_{4}(m \times n)}{S_{1}(m \times n)} ;
$$

\section{Mapping for Polarization Ellipticity (PE) Images of Polycrystalline Films of Liquor (PFL)}

The experimental research into biochemical changes in the film structure and temporal dynamics of post-mortem CSF was performed as follows:

1. Coordinate distributions of the PE image (Equation 7) values were estimated for each sample of PFL in the optical arrangement of the Stokes polarimeter (Figure 1) using the method of two-dimensional distributions of Stokes-parameters (Equations 3 to 6);

2. Measuring PE images of PFL was performed in two stages. The first involved measurements every 15 minutes during the first 6 hours after death, the second entailed one measurement every hour to 30 hours after death;

3. The statistics of the 1st to 4th order were used in the two-dimensional distributions for PE images of the PFL (Equation 2); 
4. Statistical processing of the calculated values of the set of points that characterized the PE distributions within the representative sampling was carried out; and

5. Depending on the time change, the most sensitive points of statistical values were used to achieve values stabilization.

The examples of PE images of the PFL in mapping PPL are shown in Figures 2 and 3.

Figure 2: Coordinate structure (left) and distribution histogram (right) of random values of PPL for the polarization ellipticity image, (Time 1 hour)

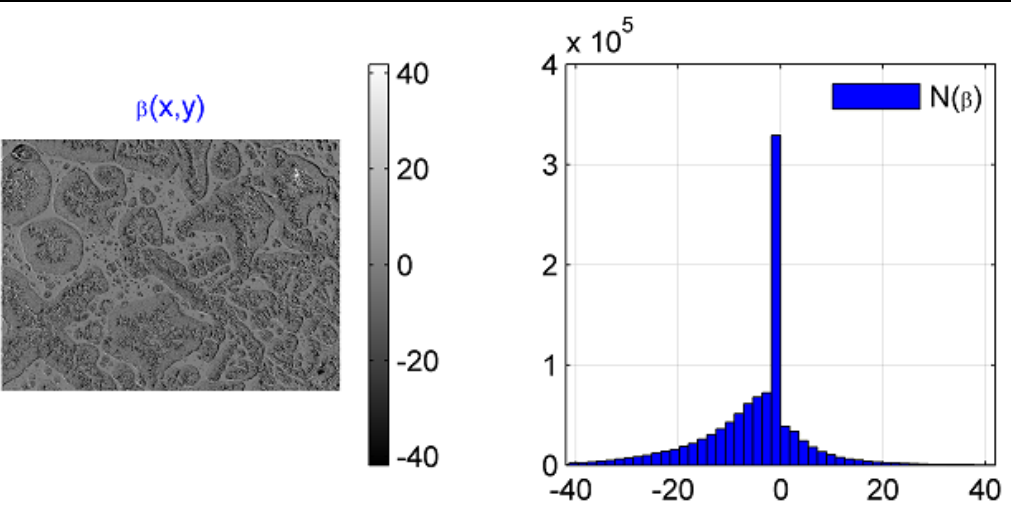

Source: Authors

Figure 3: Coordinate structure (left side) and distribution histogram (right side) of random values of PPL the polarization ellipticity (Time 12 hours)

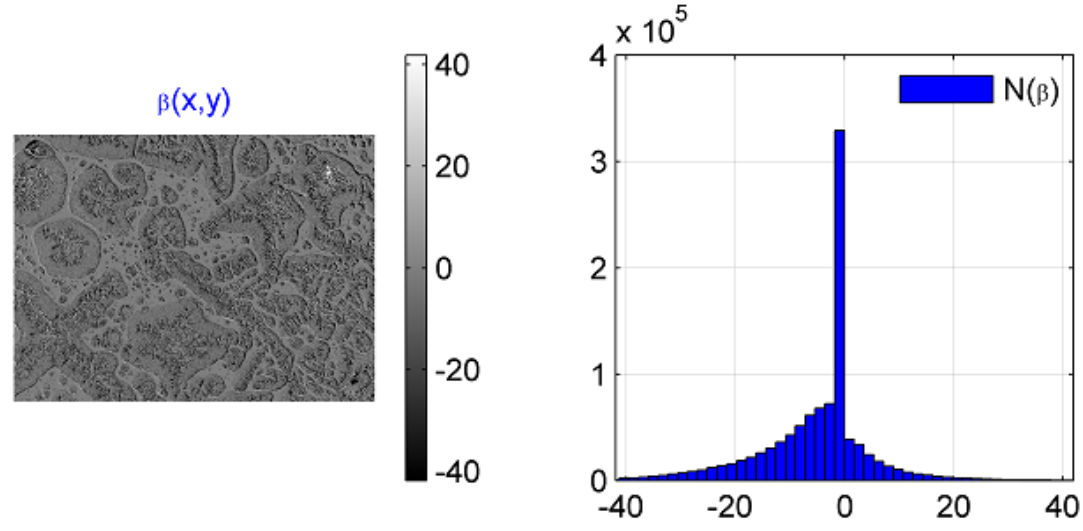

Source: Authors

Both maps of image ellipticity were not uniform (Figures 2 and 3, left) regardless of changes in observations with time-after-death.

The topological structure of PE coordinate distributions was mainly large-scale and consisted of spatially oriented fragments that were formed within this parameter of different values that showed a range of changes in the PE values in the distribution of the histogram (Figures 2 and 3, right side).

Birefringence needle molecular complexes that form the EP of laser irradiation decreased with increasing observation time.

Quantified optical displays of PFL showing degenerative changes to the needle protein network reduced the medium and dispersion of random values.

Statistics of the 3rd and the 4th order were the most sensitive PFL optical values to evaluate the postmortem changes. They characterized the PE images of the PFL with values of asymmetry and kurtosis distribution. 
Results of statistical computation for points of 3rd and 4th order, described the coordinate points for the PE image of the PFL as statistically significant for the sample within 30 hours after death (see Table 1).

Table 1: Time dependence of statistical points 3rd and 4th order, values which characterized the distribution of the polarization ellipticity image for PPL human corpse

\begin{tabular}{|l|c|c|c|c|c|c|}
\hline$T$, hours & 1 & 6 & 12 & 19 & 25 & 32 \\
\hline$Z_{3}$ & $0.48 \pm 0.03$ & $0.65 \pm 0.05$ & $0.82 \pm 0.07$ & $0.99 \pm 0.08$ & $1.16 \pm 0.09$ & $1.33 \pm 0.11$ \\
\hline$Z_{4}$ & $0.84 \pm 0.07$ & $1.02 \pm 0.08$ & $1.18 \pm 0.09$ & $1.35 \pm 0.10$ & $1.52 \pm 0.12$ & $1.69 \pm 0.13$ \\
\hline
\end{tabular}

Source: Authors

Figure 4 demonstrates the temporal change and the statistics of the 3rd and 4th order, which are the most sensitive to PFL post-mortem degradation.

Figure 4: Time dependence for the statistics of the 3rd and 4th order, values which characterized the distribution of polarization ellipticity for the PPL human corpse

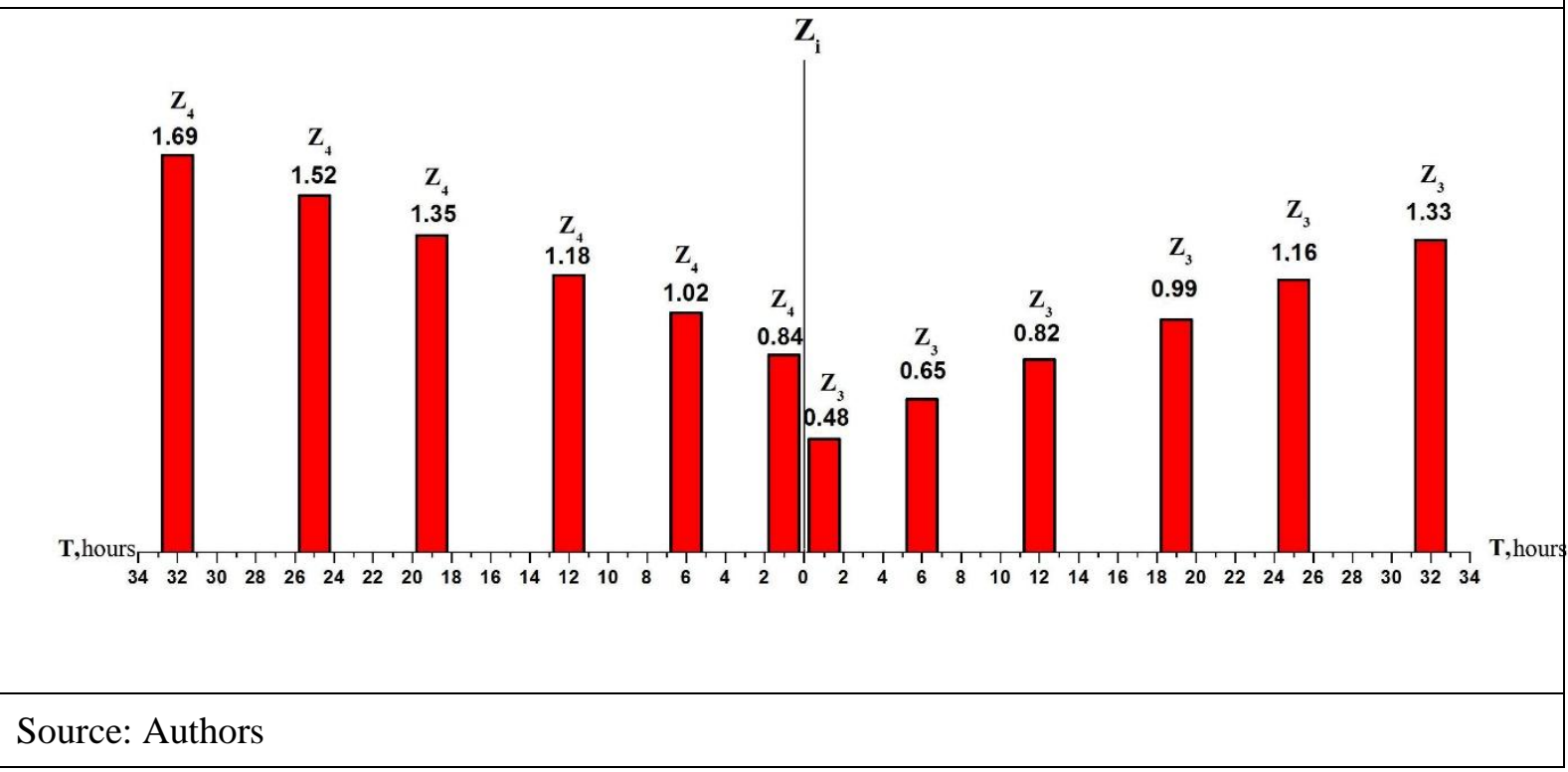

Analysis of the temporal dynamics for the statistical structure for the PE image of the PFL demonstrated that the range of variation in the statistics for the 3rd order was 2.77 times; and statistical values for the 4th order was two times.

\section{Analytical Algorithm to Estimate Post-Mortem Interval}

Figure 5 illustrates the algorithm of post-mortem interval estimation.

A chart analysis resulted in the next equation to estimate interval:

$$
\operatorname{tg} \xi=\frac{Z_{i}^{(1)}-Z_{i}^{(1)}}{T_{2}-T_{1}}=\frac{\Delta Z_{i}^{(1,2)}}{\Delta T_{12}} .
$$

Using Equation 8, we estimate time-since-death:

$$
T^{*}=Z_{i}^{(0)} \frac{\Delta T_{12}}{\Delta Z_{i}^{(1,2)}} .
$$

where $Z_{i}^{(0)}$ is the objective value, defined by a fence CSF, collected in vivo in healthy volunteers (Table 2). 


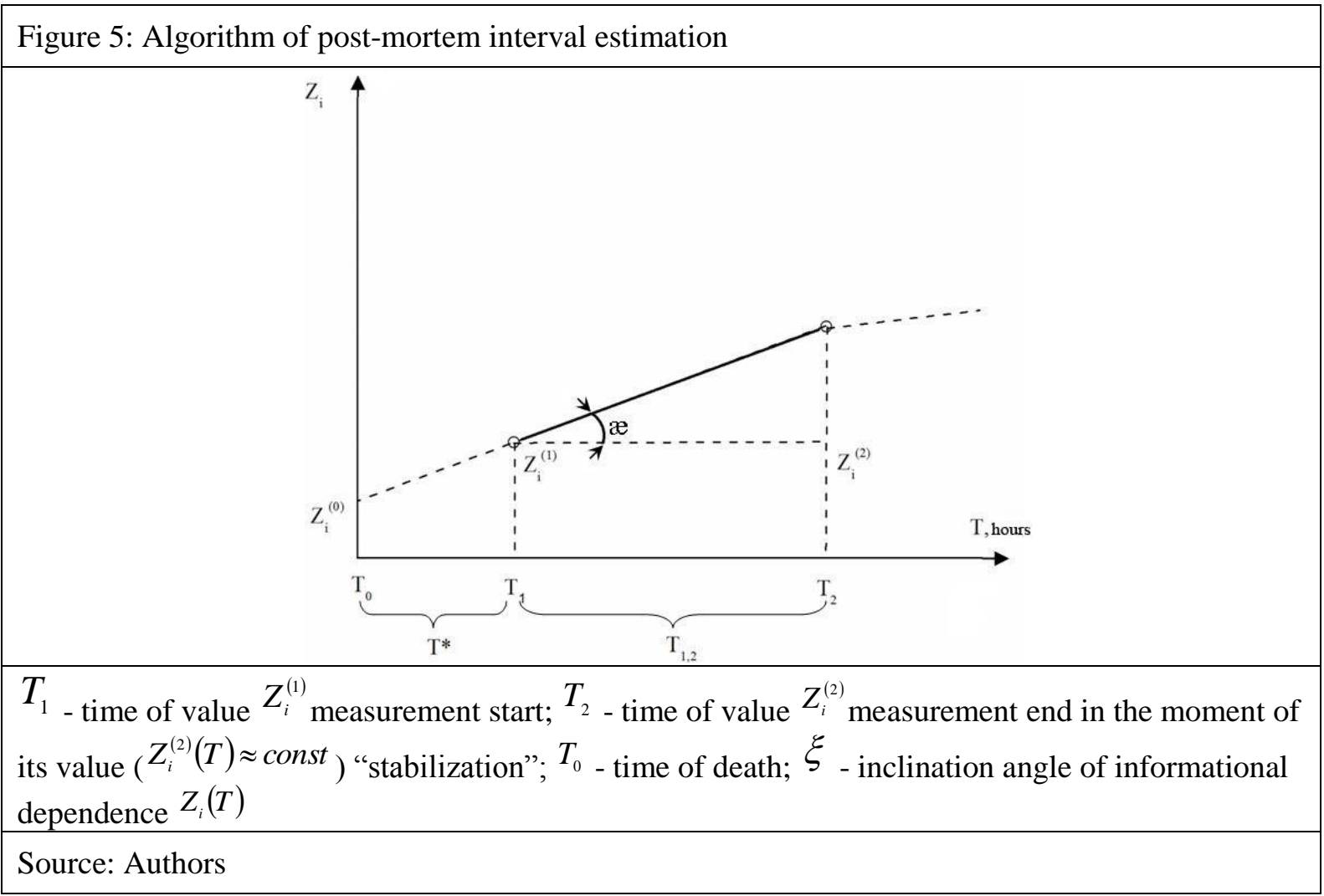

Table 2: Statistics of the 3rd and 4th order, describing the polarization ellipticity images obtained in vivo for the PPL

\begin{tabular}{|l|c|}
\hline$Z_{i}^{0}$ & PFL image ellipticity $(\beta)$ \\
\hline$Z_{3}^{0}$ & $0.11 \pm 0.085$ \\
\hline$Z_{4}^{0}$ & $0.38 \pm 0.028$ \\
\hline
\end{tabular}

Source: Authors

The established interval was 32 hours, and the accuracy of the time-since-death estimation was 60 $\min$.

\section{Conclusion}

The most sensitive to post-mortem manifestations in terms of changes to liquor polycrystalline optical networks were the statistics of the 3rd and 4th order. These characterized asymmetry and kurtosis (peak sharpness) in the values distribution for the polarization ellipticity images of polycrystalline films of liquor.

We established an optimal interval of 32 hours with the accuracy of the time-since-death estimation of $60 \mathrm{~min}$, using the method of two-dimensional Stokes-polarimetric mapping of ellipticity distributions for liquor images polarization.

\section{References}

Aksjonova, V. M., \& Starkova, A. V. (1998). Diagnosticheskaja cennost' opredelenija urovnja veshhestv srednej molekuljarnoj massy v plazme novorozhdjonnyh detej, perenjosshih vnutriutrobnuju gipoksiju. Perm. med. zhurnal, 15(1), 25-28.

Arroyo, A., Rosel, P., \& Marron, T. (2005). Cerebrospinal fluid: postmortem biochemical study. Journal of clinical forensic medicine, 12(3), 153-156. DOI: 10.1016/j.jflm.2015.09.017 
Chen, J. H., Inamori-Kawamoto, O., Michiue, T., Ikeda, S., Ishikawa, T., \& Maeda, H. (2015) Cardiac biomarkers in blood, and pericardial and cerebrospinal fluids of forensic autopsy cases: A reassessment with special regard to postmortem interval. Legal Medicine (Tokyo). 2015 Sep; 17(5): 343-50. DOI: 10.1016/j.legalmed.2015.03.007. Epub 2015 Apr 30.

Dehn, R. W., \& Asprey, D. P. (2013). Essential Clinical Procedures: Expert Consult-Online and Print. Elsevier Health Sciences. P. 146-156.

Ermakov, A. V. (2004). Izmenenie urovnja srednemolekuljarnyh soedinenij v likvore v zavisimosti ot vremeni nastuplenija smerti. Problemy jekspertizy v medicine, 4(16-4).

Finehout, E. J., Franck, Z., Relkin, N., \& Lee, K. H. (2006). Proteomic analysis of cerebrospinal fluid changes related to postmortem interval. Clinical Chemistry, Oct; 52(10):1906-13. Epub 2006 Aug 3.

Girela, E., Villanueva, E., Irigoyen, P., Girela, V., Hernández-Cueto, C., \& Peinado, J. M. (2008). Free amino acid concentrations in vitreous humor and cerebrospinal fluid in relation to the cause of death and postmortem interval. Journal of forensic sciences, 2008 May; 53(3):730-3. DOI: 10.1111/j.1556-4029.2008.00726.x.

Parmar, A. K., \& Menon, S. K. (2015). Estimation of postmortem interval through albumin in CSF by simple dye binding method. Sci Justice, 55(6), 388-393. DOI: 10.1016/j.scijus.2015.07.005

Prieto-Bonete, G., Perez-Carceles, M. D., \& Luna, A. (2015). Morphological and histological changes in eye lens: Possible application for estimating postmortem interval. Leg Med (Tokyo), 17(6), 437-442. DOI: 10.1016/j.legalmed.2015.09.002

Ushenko, O. G., Dubolazov, O. V., Ushenko, V. O., Gorsky, M. P., Soltys, I. V., \& Olar, O. V. (2015a, November). Fourier polarimetry of the birefringence distribution of myocardium tissue. In 12th International Conference on Correlation Optics (November 30, 2015, pp. 980915-980915). DOI:10.1117/12.2228980.

Ushenko, O. G., Dubolazov, O. V., Ushenko, Y. O., \& Gorsky, M. P. (2015b, November). Scale-selective analysis of myocardium polarization images in problems of diagnostic of necrotic changes. In 12th International Conference on Correlation Optics (pp. 98091C-98091C). International Society for Optics and Photonics. DOI:10.1117/12.2228998

Ushenko, V. O., Olar, O. V., Ushenko, Y. O., Gorsky, M. P., \& Soltys, I. V. (2015, November). Polarization correlometry of polycrystalline films of human liquids in problems of forensic medicine. In 12th International Conference on Correlation Optics (pp. 98091B-98091B). International Society for Optics and Photonics. DOI:10.1117/12.2228997

Wanchuliak, O. Y., Ushenko, O. H., \& Bezhenar, I. L. (2004) Application of polarization method for analyzing damage of biological tissues Bucovinian Medical Herald, 8(3-4), 300-301. 